\title{
Adaptive Overcurrent Protection Scheme for Distribution Network with
}

\section{High Penetration DG}

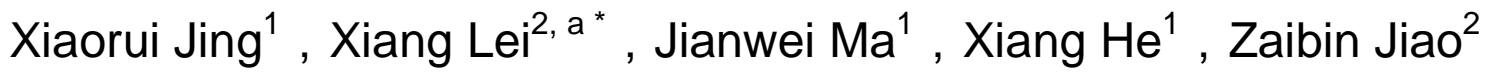 \\ 1.Henan Electric Power Company Electric Power Research Institute, Zhengzhou 450000, Henan \\ 2.School of Electrical Engineering, Xi'an Jiaotong University, Xi'an 710049, Shaanxi, China \\ a leixiang@stu.xjtu.edu.cn
}

Keywords: DG; adaptive overcurrent protection; fault component; penetration rate

Abstract. This paper presents a new adaptive overcurrent protection for distribution network with high penetration rate DG. The equivalent impedance of DG is calculated by fault components during fault transient state, and works as the premise for protection configuration. The principle and the configuration method of the adaptive overcurrent protection are provided. The proposed protection scheme adapts well to distribution networks with high penetration rate DG and solves the protection range-surpassing problem in traditional overcurrent protections, which indicates a good prospect of engineering application.

\section{Introduction}

Renewable energy has been used extensively with the depletion of fossil fuel. Distributed generation is a reasonable way to make use of renewable energy, which could guarantee the utilization efficiency and solve the problem of electricity supply in remote rural areas ${ }^{[1]}$. On one hand, the radial structure characteristic will be changed with high penetration DG to distribution network, which would bring a great challenge to traditional overcurrent protection. On the other hand, the random feature of distributed generation output makes relay configuration difficult and the requirements of selectivity and speed may not be ensured.

DGs are removed immediately once a failure occurs to the distribution network to ensure the correct operation of protecting relays. However, almost $80 \%$ of the faults in distribution network are transient faults, thus removing DGs blindly will restrict DG's normal operation and weaken the reliability of power supply ${ }^{[2-5]}$. Research of protection suitable for distribution network with high penetration DG is very necessary, and much research work has been done ${ }^{[6-10]}$.

Adaptive overcurrent protection is proposed in this paper for distribution network with high penetration DG. DG is equivalent to an ideal voltage source in series with the equivalent impedance in adaptive overcurrent protection configuration. The equivalent impedance is calculated by dint of fault components. The setting value of adaptive overcurrent protection is adjusted in reference to the equivalent impedance of DG. This protection is not affected by DG's connection point, random feature of output and its capacity.

This paper is organized as follows. Section II introduced the method to calculate the equivalent impedance. Adaptive overcurrent protection is proposed in Section III. Effectiveness of the proposed protection is validated by models established in PSCAD in Section IV. Section V concludes finally. 


\section{Equivalent impedance calculation in distribution network with DG of different capacity using fault components}

Define the ratio of DG capacity to load capacity as penetration rate, and define the ratio of the short current provided by the system under fault to the short current provided by DG as stiffness ratio. Generally, if the penetration rate is greater than $10 \%$ and the stiffness ratio is less than 20 , the influence of the DG on the distribution network should be considered.

A typical distribution network is shown in Fig.1, where A is the connection point of DG, and 1-4 represent the section switches. The bulk power system supplies power to the radial distribution network.

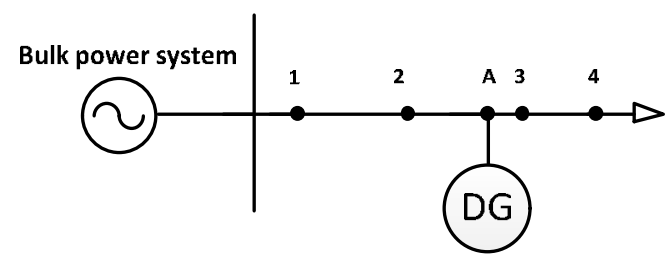

Fig.1 Structure of distribution network

According to the Thevenin theorem, the distributed generation DG can be equivalent to an ideal voltage source in series with the equivalent impedance [11]. Define ZDG as the equivalent impedance of DG, and the output capacity of DG can be represented by ZDG. ZDG is essential to the configuration of the adaptive overcurrent protection, thus method to calculate the equivalent impedance be introduced hereinafter.

When a fault K1 occurs in the distribution network as is shown in Fig.2 (a), both the bulk power system and DG will supply short current to the short point-F. The equivalent circuit of the original network with fault is shown in Fig.2 (b), which could be decomposed into the network under the normal state shown in Fig.2 (c) and the fault component network shown in Fig.2 (d). It's feasible to calculate the equivalent impedance of DG using fault components method according to Fig.2 (d).

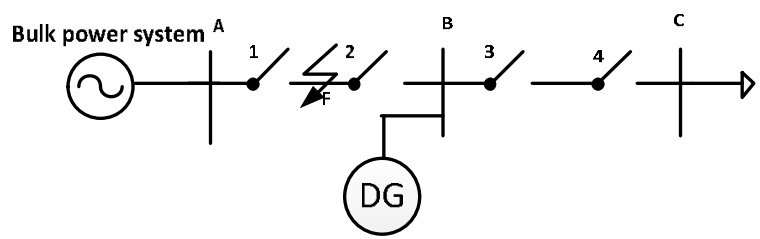

(a) the original network with fault

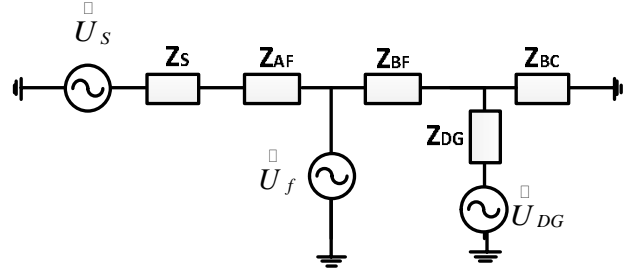

(c) network under the normal state
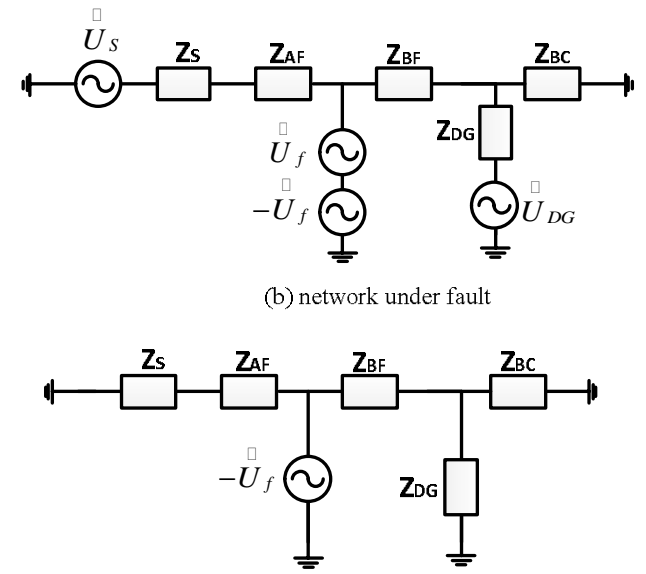

(d) the fault component network

Fig.2. Distribution network under fault

The voltage and current in normal network and short-circuit network can be measured respectively in the normal state and the state after the fault, therefore the value in fault component network can be calculated by the subtraction of normal network from short-circuit network.

The above is the analysis of single-phase network. As for three-phase network, the phase components should be transformed into sequence components by dint of symmetrical component transformation. The positive sequence fault component network is shown in Fig.3. deduced from the positive sequence short-circuit network and normal network. It is the same as the single-phase network. 


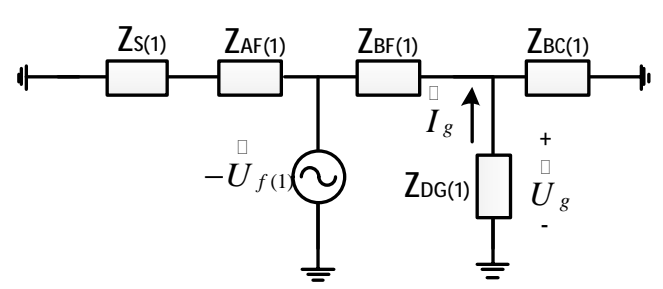

Fig. 3 positive sequence fault component network

Because fault component is not influenced by the load current and source voltage, the equivalent impedance of DG can be calculated from the positive sequence voltage and current, as equation (1) shows.

$$
Z_{D G}=-\frac{\square_{g}^{(1)}}{I_{g}^{(1)}}
$$

\section{The principle of adaptive overcurrent protection}

Adaptive overcurrent protection indicates that DG should be considered when configuring the protection. Setting calculation formula of the adaptive overcurrent protection is revised to eliminate the volatility of distributed generation output by dint of the equivalent impedance ZDG. ZDG will be modified when the output of DG changes. New setting calculation formulas are deducted hereinafter.

\section{configuration of the protection on the downstream distribution line}

Take Fig. 1 as an example, DG works as a feeding source for the protection on the downstream distribution line, thus the measured current at 3 will be enlarged. Setting of zone I-overcurrent protection of Realy3 can be given as:

$$
I_{\text {set3 }}^{\mathrm{I}}=K_{\text {rel }}^{\mathrm{I}} \cdot \frac{E_{S}\left(Z_{s}+Z_{1-A}+Z_{D G}\right)}{\left(Z_{s}+Z_{1-A}\right) Z_{D G}+Z_{3-4}\left(Z_{s}+Z_{1-A}+Z_{3-4}\right)}
$$

where $Z_{S}$ is the equivalent impedance of the bulk power system; $Z D G$ is the equivalent impedance of distributed generation; Z1-A and Z3-4 are the impedance of transmission line 1-A and 3-4. Meanwhile, $K_{r e l}^{\mathrm{I}}$ represents the reliability coefficient of zone I-overcurrent protection, generally ranging from 1.2 to 1.3 .

\section{configuration of the protection on the upstream distribution line}

Supposing the direction of power flow remains fixed when DG is integrated. Therefore, DG will provide out flowing current for the protection on the upstream distribution line [12], thus the measured current at 2 will be decreased, as Fig. 1 shows. Setting of zone II-overcurrent protection of Realy2 is shown in the following equation:

$$
I_{s e t 2}^{\mathrm{II}}=\frac{K_{r e l}^{\mathrm{II}} \cdot I_{s e t 3}^{\mathrm{I}}}{K_{b}}
$$

where $K_{r e l}^{\mathrm{Il}}$ represents the reliability coefficient of zone II, generally ranging from 1.1 to 1.2 , and $K_{b}$ is the branch coefficient.

Similar to the traditional overcurrent protection, operation of the adaptive current protection is 
determined by the comparison between the measured current and the threshold value, i.e., the breakers will be tripped to operate if the measured current is larger than the threshold setting value, otherwise, the breakers will not operate. Configuration of the delay time in the adaptive current protection is the same as traditional overcurrent protection.

As is shown in Section II, the equivalent impedance ZDG can be calculated using (1). Formulas for adaptive setting calculation equation can be deducted by substituting (1) into (2) and (3).

Flow chart of the adaptive overcurrent protection is shown in Fig.4.

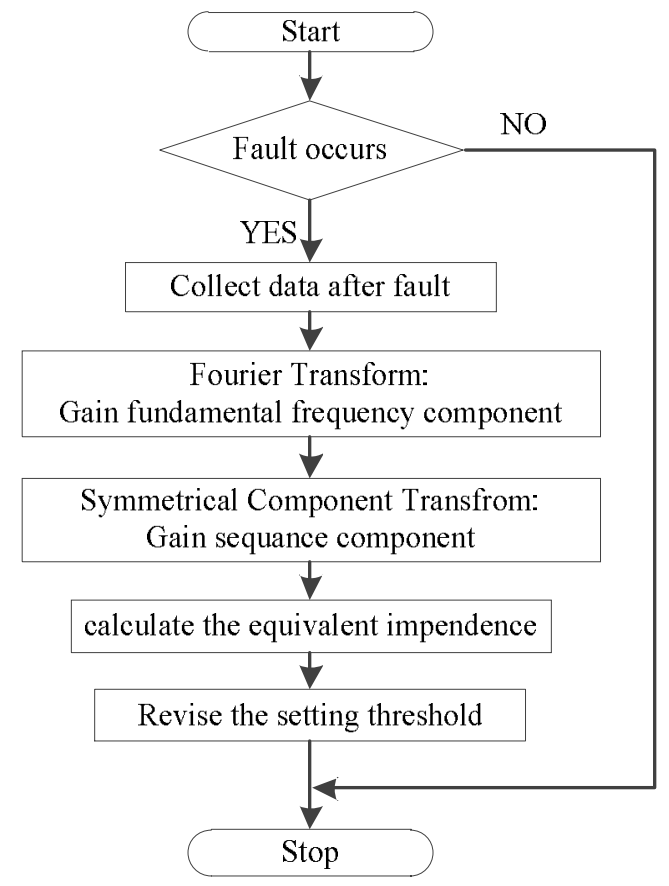

Fig.4. Flow chart of adaptive overcurrent protection

By introducing the equivalent impedance of DG to the traditional current protection setting formula, the operation value in overcurrent protection can be changed adaptively to eliminate the influence of the feed current and out flowing current, according to the capacity of DG in real time.

\section{Case Study}

A typical $10.5 \mathrm{kV}$ distribution network is established in PSCAD in this paper to validate the effectiveness of the adaptive overcurrent protection; the sketch of the model is shown in Fig.5.

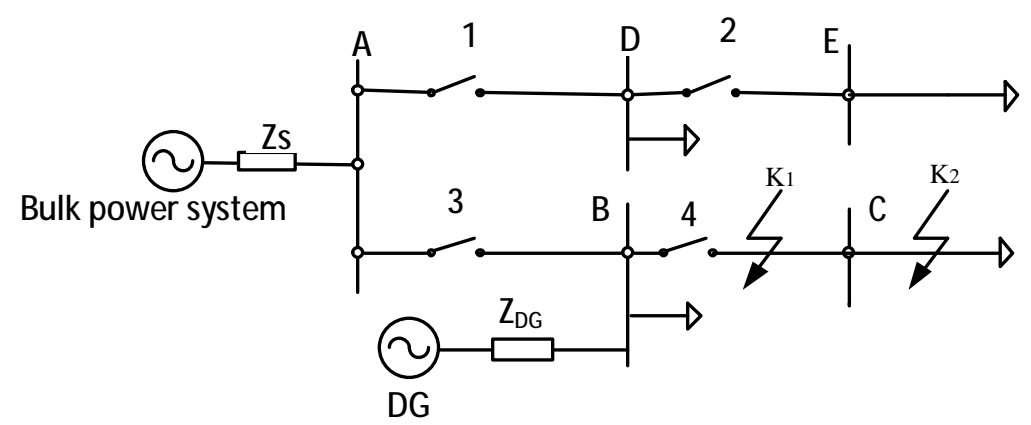

Fig. 5 Sketch of the model

\section{The influence of variety of impedance in transient period on adaptive overcurrent protection}

DGs used nowadays can be divided into two kinds: one is the rotating DG, the other is the inverter interfaced DG. The performance of traditional rotating DG and inverter interfaced DG are different in transient period after fault. This subsection will study the applicability of the adaptive 
overcurrent protection to cases with traditional rotating DG and inverter interfaced DG respectively.

\section{Traditional rotating DG}

Fig. 6 and Fig.7 provide the simulation results in distributed network model with traditional rotating DG. Fig.6 shows the current curve when an internal fault occurs at $30 \%$ of the distribution line BC, as shown in Fig. $5 \mathrm{~K} 1$. Both the measured current and the setting value verge to constants after the fault, and the adaptive overcurrent protection operate correctly since the measured current is larger than the setting value. Fig.7 shows the current curve when an external fault occurs at K2, as shown in Fig.5. The adaptive overcurrent protection will not operate since the measured current is far smaller than the setting value.

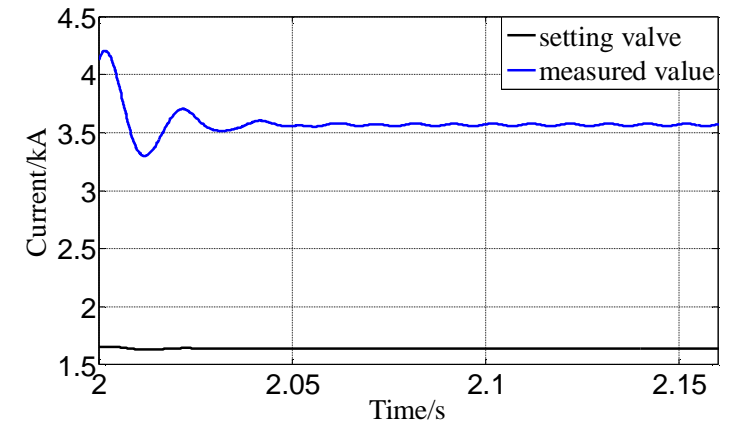

Fig.6 measured current and setting current value under internal fault

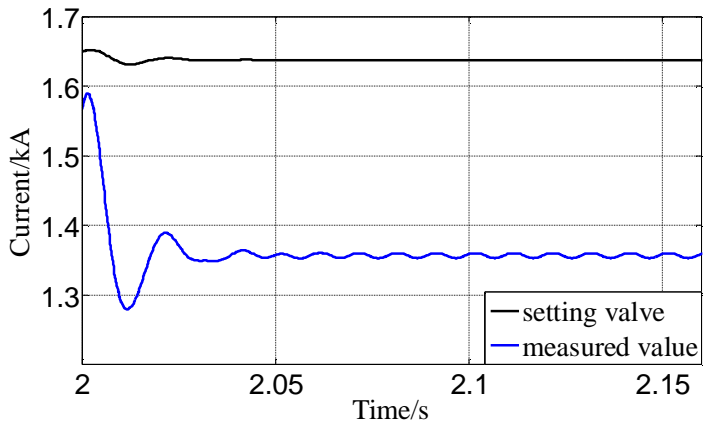

Fig.7 measured current and setting current value under external fault

The value of equivalent impedance calculated by fault component method is ideally constant due to the inertia of traditional rotating DG in fault transient period, it means that relay setting value is also a constant in that period, as is indicated in Fig.6 and Fig.7. So it is concluded that there is little influence of the variety of rotating DG's impedance in transient period on adaptive overcurrent protection.

\section{Inverter interfaced DG}

Fig. 8 and Fig.9 provide the simulation results in distributed network with inverter interfaced DG. Fig. 8 shows that when internal fault occurs, the setting current and measured current are changing constantly, but the measured current curve is above the setting value curve, i.e. the protection can operate reliability. It can be deduced from Fig.9 that adaptive overcurrent protection will not operate under external fault because the fault current curve is under the setting current curve.

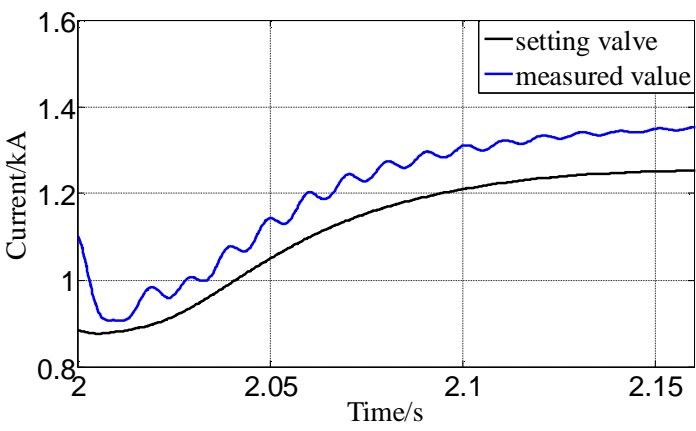

Fig.8 measured current and setting current value under internal fault

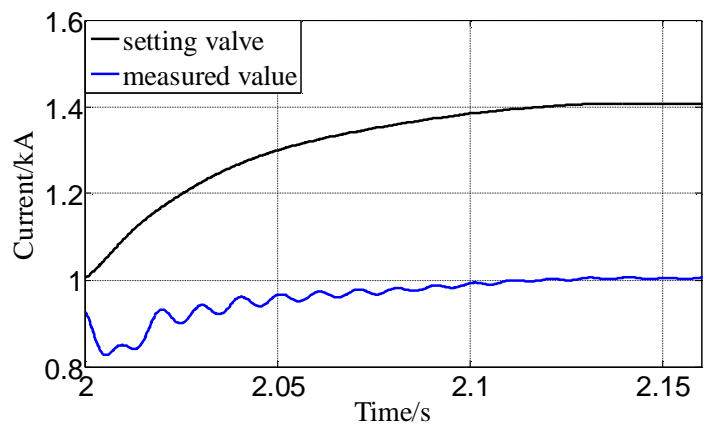

Fig.9 measured current and setting current value under external fault

Due to the transient process of inverter interfaced DG in fault transient period, the equivalent impedance of this kind of DG fluctuate upward. Meanwhile, the setting value of relay has the same trend as equivalent impedance. It means that the influence of the variety of inverter interfaced DG impedance during transient period does not affect the correct operation of the adaptive overcurrent 
protection.

\section{The influence of DG capacity fluctuation on adaptive overcurrent protection}

The DG penetration rate has an important effect on the power flow in distribution network, and results in different short-circuit current when a fault occurs. Therefore, the feasibility of the proposed adaptive overcurrent protection should be studied in distribution network with different penetration rates.

Simulations are carried out in PSCAD, and three different penetration rates are considered: $15 \%$, $33 \%$ and $50 \%$. Traditional rotating DG model is used in the simulation. Curves of the measured current and the setting value are shown in Fig.10.
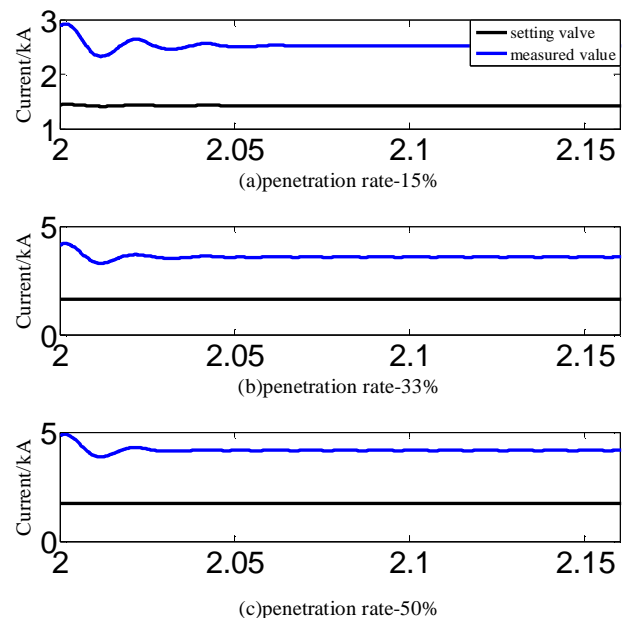

Fig.10 current curve under different penetration rate (traditional rotating DG)
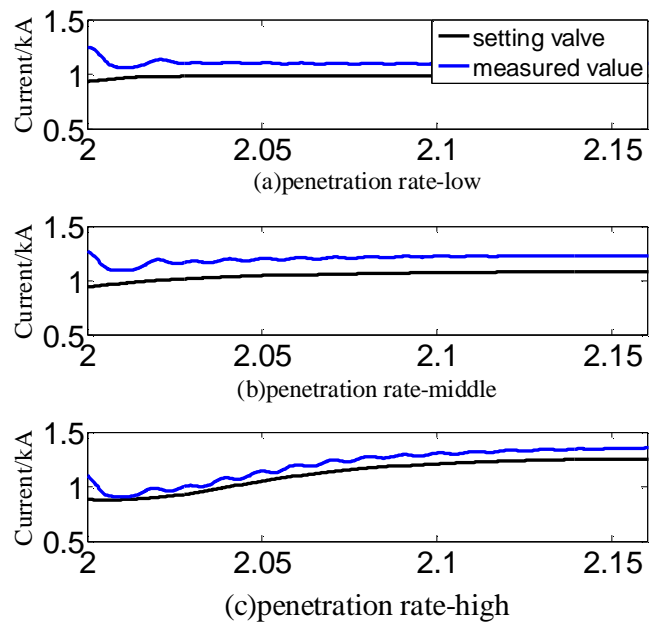

Fig.11 current curve under different penetration rate (inverter interfaced DG)

It can be observed from Fig.10 that the measured current is always larger than the setting value under different penetration rate, thus the adaptive overcurrent protection could operate correctly. The same conclusion could be made when inverter interfaced DG is used, as is shown in Fig.11. Further studies show that the protection domain merely varies under different penetration rate because the setting value will change adaptively, so the adaptive overcurrent protection has great adaptability in distribution network with DG.

The comparison between adaptive overcurrent protection and traditional overcurrent protection

In adaptive overcurrent protection algorithm, the threshold is set adaptively. The threshold depends on the penetration rate. The protection domain of zone I-overcurrent protection of Relay 4 and zone II-overcurrent protection of Relay 3 are given in Tab.1, and the protection domain of the traditional overcurrent protection is also provided as a comparison.

Table1. Protection domain of adaptive current protection under different penetration rates

\begin{tabular}{ccc}
\hline & $\begin{array}{c}\text { protection domain of } \\
\text { zone I Relay 4 }\end{array}$ & $\begin{array}{c}\text { protection domain of } \\
\text { zone II Relay 3 }\end{array}$ \\
\hline Adaptive overcurrent protection (33\%) & $72 \%$ & $62 \%$ \\
Adaptive overcurrent protection (20\%) & $70 \%$ & $63 \%$ \\
Adaptive overcurrent protection (13\%) & $71 \%$ & $62 \%$ \\
Traditional overcurrent protection & $121 \%$ & 0 \\
\hline
\end{tabular}

Percentage in the table stands for the penetration rate. It can be concluded from Tab.1 that traditional overcurrent protection will mal-operate or refuse to operate. The range of the main protection can still reach $70 \%$ of the faulted line, while the backup protection can extend to, at least, 
$60 \%$ of downstream line. Suitable protection domain could be guaranteed in adaptive overcurrent protection. Thus the reliability and selectivity of adaptive overcurrent protection is enhanced in adaptive overcurrent protection.

\section{Conclusion}

Since the traditional overcurrent protection in distribution network could not operate correctly with DG access, this paper presents a new adaptive overcurrent protection for distribution network with high penetration DG. Conclusions could be made through the analysis.

(1) The adaptive overcurrent protection could operate correctly when the capacity of DG is fluctuating, which makes up for the disadvantages of traditional overcurrent protection.

(2) Compared with traditional overcurrent protection, the adaptive overcurrent protection could guarantee the protecting range, thus the reliability and selectivity are enhanced.

(3) The adaptive overcurrent protection isn't influenced by fault type, fault location, transient changes and DG penetration. Main protection and backup protection can both operate correctly.

\section{References}

[1] Lv Dianjun. Control Strategy Research of Micro-grid [D]. Harbin Industrial University. 2013(06).

[2] Brahma S M . Development of adaptive protection scheme for distribution systems with high penetration of distributed generation[J] .IEEE Transactions on Power Delivery 2004, 19(1): $56-63$.

[3] Ahmad Razani Haron, Azah Mohamed, Hussain Shareef. Analysis and Solutions of Overcurrent Protection Issues in a Microgrid. 2012 IEEE International Conference on Power and Energy, 2012: 644-649

[4] Baran M , El-Markabi I . Adaptive over current protection for distribution feeders with distributed generators [C]//IEEE PES on Power Systems Conference and Exposition , New York ,

America , $2004: 715-719$.

[5] Ochoa L.F, Padiha-Feltrin A, Harrison G.P. Evaluating distributed generation impacts with a multi-objective index [J]. IEEE Transactions on Power Delivery, 2006, 21(3): 1452-1458

[6] G. Rockefeller. Adaptive transmission relaying concepts for improved performance [J]. IEEE Trans. Power Del., vol. 3, no. 4, pp.1446-1458, Oct. 1988.

[7] K. Kauhaniemi and L. Kumpulainen. Impact of distributed generation on the protection of distribution networks[C]. in Proc. 2004 Developments in Power System

[8] Pukar Mahat, Zhe Chen, Birgitte Bak-Jensen and Claus Leth Bak. A Simple Adaptive Overcurrent Protection of Distribution Systems With Distributed Generation [J]. IEEE Transactions on smart grid., vol. 2, no. 3, pp. 428-437, 2011.

[9] W. El-khattam and T. S. Sidhu. Resolving the impact of distributed renewable generation on directional overcurrent relay coordination: A case study [J]. IET Renew. Power Gen., vol. 3, pp. 415-425, 2009.

[10] A. Agheli, H. A. Abyaneh, R. M. Chabanloo, and H. H. Dezaki, Reducing the impact of DG in distribution networks protection using fault current limiters [C]. in Proc.4th Int. Power Eng. 
Optimiz. Conf., 2010, pp.298-303.

[11] Ge Yaozhong. Principle and technology of new type of relay protection and fault location [M]. Xi'an Jiaotong University Press. 2007(2)

[12] Zhang Baohui, Yin Xianggen. Power System Protective Relaying [M]. China Electric Power Press. 2010(2) 